ISSN: $2317-8957$

Volume 6, Number 2, Dec. 2018

\title{
EDUCAÇÃO PARA O CONSUMO CONSCIENTE: ANÁLISE DE PRÁTICAS SOCIO- AMBIENTAIS NA CIDADE DE ITAPERUNA/RJ
}

\author{
RAPHAEL DE ANDRADE RIBEIRO*, WENDEL MATTOS POMPILHO
}

\author{
Universidade Federal Fluminense, Instituto do Noroeste Fluminense de Educação Superior, Departamento de Ciências Exatas, Biológicas e da \\ Terra. Programa de Mestrado em Ensino. Santo Antônio de Pádua, RJ. Brasil. \\ *E-mail para contato: raphaeldeandrade@bol.com.br
}

\section{RESUMO}

A problematização relacionada aos impactos ambientais gerados pelo consumismo populacional é uma realidade constantemente debatida por aqueles, que em veracidade, se preocupam com o atual cenário em que a natureza se encontra. Nesta perspectiva o presente estudo pressupõe a importância da compreensão do consumo consciente, por intermédio da difusão de métodos educacionais específicos e adequados à resolução dos problemas ambientais na cidade de Itaperuna, em virtude de sua população ter gerado no ano de 2016, o quantitativo de 1,26843 kg/hab./dia de Resíduos Sólidos Urbanos, excedendo a média de 1,040 kg/hab./dia, divulgada pela Associação Brasileira de Empresas de Limpeza Pública e Resíduos Especiais, pertinente ao mesmo ano. Neste diapasão, para consolidar o objetivo proposto utilizou-se métodos quantitativos e análises bibliográficas com o objetivo de averiguar e ponderar a respeito da proporção em que as ações sustentáveis compreendidas no questionário foram cotidianamente fixadas, pelos 758 pesquisados residentes na cidade de Itaperuna/RJ. Por fim, os resultados apresentados convergem com o problema abordado, realçando a incompatibilidade entre as ações sustentáveis estabelecidas por estas e a "consciência verde" do público investigado.

Palavras-chave: Consumismo. Resíduos sólidos urbanos. Educação. Consumo sustentável.

\begin{abstract}
The problematization related to the environmental impacts generated by the population consumerism is a reality constantly debated by those, who in truth are concerned with the current scenario in which the nature is. In this perspective, the present study presupposes the importance of the understanding of the conscious consumption, through the diffusion of specific educational methods and adequate to the solving of the environmental problems in the city of Itaperuna, because its population generated in the year 2016, the quantitative of $1.26843 \mathrm{~kg} / \mathrm{day} / \mathrm{day}$ of Urban Solid Waste, exceeding the average of $1.040 \mathrm{~kg} / \mathrm{hab} /$ day, published by the Brazilian Association of Public Cleaning and Special Waste Companies, applicable to the same year. In order to consolidate the proposed objective, quantitative methods and bibliographical analyzes were used to ascertain and ponder the proportion of sustainable actions included in the questionnaire, which were daily fixed by the 758 respondents living in the city of Itaperuna. Finally, the presented results converge with the problem addressed, highlighting the incompatibility between the sustainable actions established by them and the "green conscience" of the public investigated.
\end{abstract}

Keywords: Consumerism. Urban Solid Waste. Education. Sustainable consumption.

\section{INTRODUÇÃO}

A dinâmica do consumo excessivo, fixada pela população dos países desenvolvidos, é reconhecia atualmente como uma prática comum e crescente, tornando-se nos últimos anos uma problematização, que tem fomentado a in- tensificação do desequilíbrio natural, estabelecido pela relação desproporcional do homem com o meio ambiente (COPETTI, FRIZZO, 2009).

$\mathrm{Na}$ mesma perspectiva, países emergentes, como o Brasil, apresentam taxas crescentes no que se refere ao consumo exacerbado de suas populações, acentuadas pela dinâmica do êxodo 
rural e pelas oportunidades de emprego ofertadas pelas cidades promovendo melhorias nos padrões de vida dos brasileiros e consequentemente aumentando o volume de Resíduos Sólidos Urbanos (RSU), construindo um cenário desafiador para os municípios que não conseguem atender as necessidades da coleta de lixo ou não disponibilizam locais devidamente planejados para acomodá-los, dispondo-os em terrenos abandonados seguidos de sua queima (COPETTI, FRIZZO, 2009; MATOS, 2012; MORAES; SARTORI; LIMA, 2017).

A justificativa para a realização desta pesquisa se encontra nas informações disponibilizadas pela SMO (2017apud Moraes; Sartori; Lima, 2017), de que em 2016, a população que residiu no município de Itaperuna/RJ, gerou 1,26843 kg/hab./dia de Resíduos Sólidos Urbanos, superando a média nacional, estimada pela ALBREPE - Associação Brasileira de Empresas de Limpeza Pública e Resíduos Especiais (2016), que é a de 1,040 kg/hab./dia.

A importância em se abordar o tema da complexidade que envolve a preservação ambiental, decorre da percepção sobre o incipiente processo de reflexão acerca das poucas práticas sustentáveis que em veracidade são fixadas por cada cidadão e também, pelas múltiplas possibilidades de pensar na realidade complexa vivenciada por esta sociedade, viabilizando um novo modo de pensar e agir onde o homem e a natureza articulam-se de forma estável.

Nessa conjuntura, é perceptível que mediante a necessidade de se preservar o meio ambiente em que a sociedade está inserida, se tornou constante a preocupação e a discussão acerca da evolução da intensa degradação ambiental, acarretando na manifestação do ordenamento jurídico nacional e internacional, grupos ambientalistas e movimentos socioambientais em prol de estudos, reflexões e diagnósticos para promover ações estratégicas para proteção e preservação da natureza.

Para a elaboração deste estudo, destacase o uso da metodologia quantitativa, como instrumento de coleta de dados e a investigação bibliográfica, como parâmetro para ponderar sobre os dados tabulados.

Assim sendo, esta pesquisa tem como objetivo de analisar a proporção em que as ações sustentáveis compreendidas no questionário são efetivadas pelos indivíduos residentes na cidade de Itaperuna/RJ.

\section{REFERENCIAL TEÓRICO}

Toda sociedade, para se manter em desenvolvimento, precisa que o consumo de sua população, esteja padronizado com as necessidades destas, de maneira que haja um equilíbrio entre o que é ofertado e o que é consumido. Está prática pode ser compreendida como um conjunto de ações realizadas pela população em geral, a partir da prestação de serviços, fabricação de produtos, compras, vendas, e assim por diante, visando atender das necessidades básicas para a sobrevivência do homem (CASTAÑEDA, 2010).

Na mesma conjuntura, Bauman (2008, p. 37) explica:

[...] o consumo é uma condição, e um aspecto, permanente e irremovível, sem limites temporais ou históricos; um elemento inseparável da sobrevivência biológica que nós humanos compartilhamos com todos os outros organismos vivos. Visto desta maneira, o consumo tem raízes tão antigas quanto os seres vivos... qualquer modalidade de consumo considerada típica de um período específico da história humana pode ser apresentada, sem muito esforço, como uma versão ligeiramente modificada de modalidades anteriores.

Todavia, o que se torna relevante para este estudo, é a realidade de que na contemporaneidade, tal hábito é fixado de forma exorbitante e descontrolado, sendo intitulado por muitos pesquisadores como consumismo, impulsionado pela intensificação pela Revolução Industrial, em meados do século XIX, devido ao aumento da produção industrial fixado após a Segunda Guerra Mundial (BARBOSA, 2004; PEREIRA, HORN; 2009).

Deste diapasão, a sociedade começou a reestruturar a prática do consumo, sob um molde ia além das necessidades básicas para sobreviver. Por conseguinte, o consumo começou a 
ser estabelecido pelo homem como uma atividade crescente e intensa, fundamentada na dinâmica de apropriação e descarte, em ritmo acelerado.

No que se relaciona a esse modelo de consumo excessivo, Pereira e Horn (2009, p. 13) esclarecem:

Foi idealizada a exigência de que fizesse do consumo uma forma de vida, que a compra e o uso de bens fossem ritual; que a satisfação espiritual e a satisfação do ego fossem buscadas no consumo, que as coisas, fossem consumidas destruídas e descartadas em um ritmo cada vez maior.

Esse modelo inovador imposto à população pela sociedade capitalista, através das ferramentas da globalização, como o marketing, por exemplo, estimulam o ser humano a desenvolver necessidades ligadas à obtenção compulsiva de bem materiais, de maneira a satisfazer os desejos de seu ego (BAUMAN, 2007; GODECKE et al., 2013).

Sob a mesma lógica, Kremer (2007) complementa a abordagem acima, afirmando a existência de situações em que o indivíduo, para satisfazer suas necessidades exageradas de consumo, fixa acordos com instituições financeiras, que se aproveitam da situação, ofertando o valor necessário a altas taxas de juros, gerando assim um grande déficit econômico para sua vida.

Nessa mesma perspectiva, é visto que o consumismo fomentou uma nova forma do homem ver a sociedade em que está inserido, onde determinas práticas, lhe são tidas como comuns, ou seja:

As atividades cotidianas condicionam o morador urbano a observar determinados fragmentos do ambiente e não perceber situações com graves impactos ambientais condenáveis. Casos de agressões ambientais como poluição visual e disposição inadequada de lixo refletem hábitos cotidianos em que o observador é compelido a conceber tais situações como "normais". Andar pela cidade e contemplar os fragmentos habituais - regiões do ambiente urbano que compõem esse ecossistema - permite observar paisagem que retrata hábitos edificados temporal e culturalmente. Muitos são visíveis e se apresentam no mosaico de possibilidades da cena urbana. No entanto, nem sempre tais circunstâncias são percebidas e o morador local, pela vivência cotidiana habitual, não reflete sobre o contexto onde vive (MUCELIN; BELLINI, 2008, p. 114).

Diferente do cenário abordado pode-se perceber que algumas pessoas preservam determinadas práticas voltadas para o desenvolvimento sustentável, de modo que seu consumo seja estabelecido sem causar danos à natureza. (PORTILHO, 2005).

Para Godecke et al. (2013), as práticas de consumo sustentável precisam ser estabelecidas pela população com grande urgência, essencialmente quando se considera o aumento populacional, a intensificação do consumismo e a degradação da natureza.

Destarte, salienta-se que o consumidor ocupa uma posição pertinente na sociedade, em virtude de sua capacidade precípua de consumo. Por essa razão,

[...] a prática do consumo consciente deve ser realizada no dia a dia, mediante atos simples, que levem em consideração o impacto da compra, o uso racional e adequado dos bens e produtos, o descarte correto, bem como a preferência por empresas que possuam responsabilidade ambiental (VIEIRA; COSTA 2015, p. 279).

Neste enquadramento diversas ações já vêm sendo adotadas para aliviar o impacto ecológico, gerado por toda dinâmica capitalista, exemplificadas por intermédio da reciclagem, da coleta seletiva, da geração de energia elétrica provenientes de fontes naturais, da redução de uso de aditivos na agricultura, do uso de filtro nas chaminés das indústrias, dentre outras ações (GODECKE et al., 2013).

No entanto, Ester et al. (2004) evidencia um aspecto pertinente para este estudo, que é a veracidade de que apesar das ações de conscientização e preservação ambiental fixadas na sociedade é visto a existência de discordâncias entre a consciência ambiental de cada indivíduo e a sua forma de agir.

A autenticidade desses argumentos, segundo Ester et al. (2004), foi notabilizada por intermédio de pesquisas como a Global Environmental Survey (GOES), que buscou averiguar as alterações dos valores culturais, 
fixados nas sociedades ocidentais e não-ocidentais, onde estas influenciaram as preocupações, as ações e os comportamentos individuais referentes ao meio ambiente.

Straughan e Roberts (1999) assim como, Kalafatis et al. (1999), explicam essa circunstância elucidando a existência do intitulado "comportamento verde", proveniente da "consciência ecológica", isto é, o impacto que os indivíduos tem sobre as ações que influenciam a preservação ou a degradação do meio ambiente.

No mesmo contexto, Moisander e Pesonen (2002), definem o "comportamento verde" como uma prática essencialmente ética, norteada por suas necessidades em concordância com o bem-estar da sociedade em que vive.

Ainda sob este viés argumentativo, Stern, et al. (1995), complementam que a cultura social dominante, é reconhecida como um fator primordial que tende a conduzir o comportamento individual e/ou público, perante os problemas ambientais existentes no meio em que vivem.

[...] Em muitas culturas, as mudanças fundamentais no valor provocaram crescente preocupação ambiental, juntamente com o apoio público à proteção ambiental.

Além de atender ao desafio objetivo da degradação ambiental, as mudanças no valor cultural provocaram expressões públicas de preocupação e determinaram sua vontade de fazer sacrifícios e realizar ações para ajudar a proteger o meio ambiente (ESTER et al. 2004, p. 45).

Segundo Afonso (2006), Zanirato e Rotondaro (2016), para que os hábitos sustentáveis sejam alcançados, é preciso tempo e adaptação por parte de cada pessoa. As alterações inerentes a esse processo dependem de uma renovação, essencialmente educacional, que ressalte a relevância das consequências das ações individuais na natureza.

Assim sendo, infere-se que mediante as ações voltadas para a preservação e conservação da natureza, torna-se pertinente estabelecer um alinhamento nas atividades executadas pela população.

Por conseguinte, em conformidade com Vieira e Costa (2015), faz-se necessário desen- e introduzir na sociedade, por meio de práticas educacionais, uma cultura que reduza os impactos no meio ambiente, através da padronização do pensamento humanos, com suas ações, de forma que este consiga controlar seus impulsos de consumo e evite desperdícios.

\section{METODOLOGIA}

A realização desta pesquisa científica foi consolidada mediante as respostas de 758 pesquisados obtidas por meio de um questionário com perguntas fechadas elaboradas de acordo com o objetivo almejado - que foi o de analisar a proporção em que determinas práticas sustentáveis compreendidas no questionário foram cotidianamente realizadas pelos indivíduos residentes na cidade de Itaperuna/RJ.

Todavia, para se alcançar os objetivos inicialmente propostos, um delineamento sobre a estrutura da pesquisa e o método utilizado, foram minuciosamente selecionados, visando atender as exigências do objetivo proposto. Diante disto, a escolha da metodologia quantitativa foi considerada como a mais conveniente para se chegar às ponderações finais (MARCONI; LAKATOS 2006).

Foram realizados doze questionamentos, onde os pesquisados poderiam assinalar apenas uma das cinco opções de resposta, sendo estas apresentadas na seguinte ordem: sempre, na maior parte das vezes, ocasionalmente, quase nunca e nunca.

Além das vertentes descritivas contidas nesta pesquisa, cabe ressaltar sua essencial exploratória, uma vez sua realização possibilitou a busca de novas informações sobre o tema proposto, como é ratificado por Cervo, Bervian e Silva (2007, p. 63) "a pesquisa exploratória não requer a elaboração de hipóteses a serem testadas, restringindo-se a definir objetivos e buscar informações sobre determinado assunto de estudo".

\section{RESULTADOS}

Foi confeccionado um questionário de cunho objetivo/subjetivo, estruturado em 12 questões objetivas onde os pesquisados poderiam assinalar apenas uma das cinco opções de 
resposta, sendo estas apresentadas na seguinte ordem: sempre, na maior parte das vezes, ocasionalmente, quase nunca e nunca. A qual norteou a abordagem aos entrevistados e proporcionou traçar o perfil dos habitantes do $\mathrm{Mu}-$ nicípio de Itaperuna/RJ, evidenciando elementos de seu comportamento e relação com meio ambiente, com a intenção de o de analisar a proporção em que determinas práticas sustentáveis no seu dia a dia.

A fim de fornecer maior clareza sobre a forma de coleta dos dados, apresenta-se a seguir o questionário utilizado que serviu à construção do perfil do comportamento e da responsabilidade socioambiental dos sujeitos envolvidos nessa pesquisa. Os dados foram submetidos a uma análise quantitativa, seguida de um exercício interpretativo baseado nos fundamentos teóricos apresentados anteriormente.
A presente pesquisa é caracterizada como quantitativa e qualitativa, cujo instrumento de utilizado para coletar os dados foi o questionário readaptado da obra de Paestoreet al (2015), associado às investigações bibliográficas fundamentadas em estudiosos do assunto em questão.

Os dados apresentados, na Tabela 1, demostraram os percentuais referente às respostas a cada pergunta, dos 758 pesquisados.

Os valores obtidos comprovaram a existência de divergências entre as práticas sustentáveis fixadas no questionário e o que em veracidade é realizado, na cidade onde a pesquisa foi elaborada, podendo estes ser estabelecidos em função da cultura populacional disseminada.

Aparentemente, mediante os resultados obtidos é visto a existência de uma postura ética em relação ao meio ambiente, porém desalin-

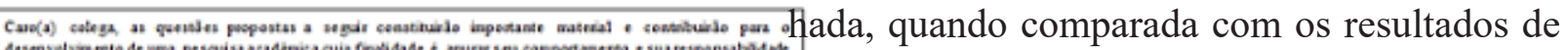

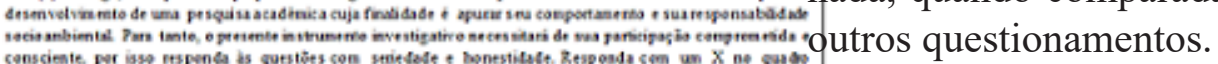

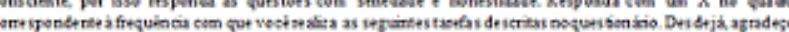
auz coctrituigio.

${ }^{1} \mathrm{O}$ questionário foi retirado e readaptado da obra de Paestore et al (2015).

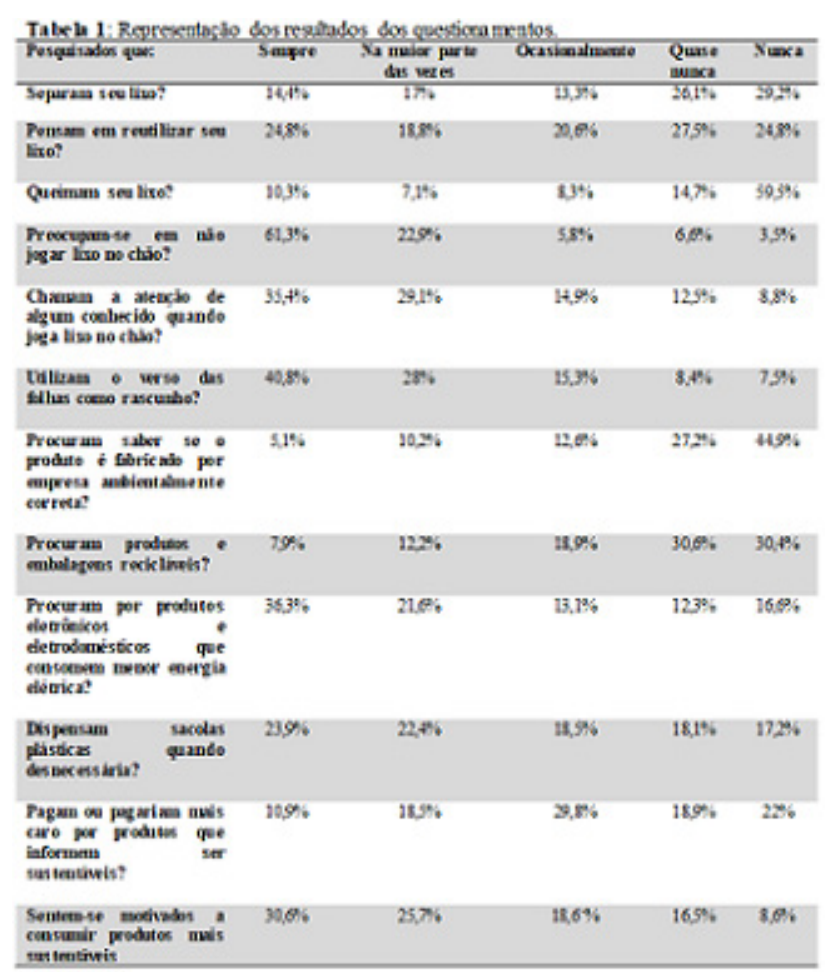

Os números quantificados permitiram inferir que os pesquisados apresentam algum tipo de envolvimento com o "comportamento verde" difundido na sociedade através da cultura vigente, que é essencialmente diferenciada das práticas conscientes de conservação e preservação da natureza.

A análise e a reflexão dos dados aqui expostos, não insinuam a inexistência de quaisquer práticas sustentáveis fixadas por esta população, mas sim perceber os índices de ações sustentáveis estabelecidos por elas em seu dia a dia, uma vez que a produção de Resíduos Sólidos Urbanos, na cidade de Itaperuna, no ano de 2016, superou a média nacional divulgada pela ALBREPE (2016).

Assim sendo, é claramente perceptível que a temática ambiental e social se fundamenta na realidade inseparável do homem com meio natural, pois ambos interagem e inter-relacionam- se entre si. A degradação ambiental parte da relação deturpada e descomprometida, onde homem parte da premissa de usar o meio ambiente para seu conforto e bem-estar, sem estar preparado adequadamente para interagir com o 
meio sem alterá-lo, degradá-lo ou extremista, destruí-lo, que produz esgotamento dos recursos naturais e exploração do homem pelo homem.

\section{CONSIDERAÇÕES FINAIS}

A realização desta pesquisa científica teve como principal objetivo averiguar a proporção das ações socioambientais, fixadas pelas pessoas que residem em Itaperuna, em seu cotidiano, através dos dados obtidos por meio da aplicação do questionário. Consequentemente ficou evidente que existe uma desarmonia entre as ações estabelecidas pela população em seu dia a dia e a preocupação destas com o meio ambiente.

Atualmente os problemas ambientais assumem um grande destaque e relevância social, ecológica, econômica, cultural, dentre outras, cada vez em proporções mais alarmantes e nocivas para a população. Diante desses fatores nasce a necessidade de debates, reflexão, mobilização, conscientização para atuar de maneira ativa e comprometida em defesa do meio ambiente natural e do meio social baseada na relação do homem com seu meio.

Os conceitos de desenvolvimento sustentável e responsabilidade socioambiental, assim como analisado pelo presente estudo, surgem em meio a um processo de desenvolvimento e crescimento desordenado, baseado em um sistema de produção e consumo desenfreado. É nesse contexto que surgem as primeiras críticas e perspectivas de mudanças sobre tais posturas.

É essencial para impulsionar as transformações de uma educação que assume um compromisso com a formação de uma visão crítica, de valores e de uma ética para a construção de uma sociedade ambientalmente sustentável. A necessidade de uma crescente internalização da questão ambiental, um saber ainda em construção, demanda um esforço de fortalecer visões integradoras que, centradas no desenvolvimento, estimulam uma reflexão em torno da diversidade e da construção de sentidos nas relações indivíduos-natureza, nos riscos ambientais globais e locais e nas relações ambiente- -desenvolvimento.

Não obstante, com os exemplos, análises e argumentos produzidos ao longo desta pesquisa é possível afirmar que determinados hábitos não condizem com o cuidado que estes têm com a natureza, justificando assim a necessidade do desenvolvimento de uma cultura que estimule os indivíduos a executarem práticas voltadas à preservação e conservação da natureza.

Assim, mediante os fatos apurados e a pesquisa bibliográfica realizada, nota-se que não há, ainda, nenhum movimento significativo de ruptura com as relações sociais capitalistas e de construção de um novo padrão societário. Pelo contrário, reforça a ideologia liberal por meio do uso discursivo de que esta nova sociabilidade é o que há de possível e mais adequado no cenário contemporâneo.

Por fim, vale salientar que as informações obtidas e quantificadas nesta pesquisa podem ser consideradas superficiais, mediante alegações indutivas. Portanto, há a recomendação de se averiguar essa problematização através de outras metodologias e outros públicos, possibilitando assim, que uma exploração mais consciente seja estabelecida.

\section{REFERÊNCIAS}

ABRELPE - Associação Brasileira de Empresas de Limpeza Pública e Resíduos Especiais. Panorama dos Resíduos Sólidos no Brasil 2016. $10^{a}$ ed. São Paulo, 2016.

AFONSO, C. M. Sustentabilidade: Caminho ou utopia?São Paulo: Annablume, 2006.

AJZEN, I.; FISHBEIN, M. Attitudinal and normative variables as predictors of specific behavior. Journal of Personality and Social Psychology, v. 27, n.1, p. 41-57, 1973.

BARBOSA, L. Sociedade de Consumo. 3. ed. Rio de Janeiro: Zahar, 2004.

BAUMAN, Z. Vida líquida. Rio de Janeiro: Jorge Zahar, 2007. 
Vida para consumo: a transformação das pessoas em mercadorias. Tradução: Carlos Alberto Medeiros. Rio de Janeiro: Jorge Zahar, 2008.

CASTAÑEDA, M. Teorias das práticas na análise do consumo. Revista Ciências Sociais Unisinos, São Leopoldo - RS, v. 46, n. 3, p. 248-255, 2010.

CAVIGNATO, D. Análise do consumo sustentável na Escola de Educação Infantil Antônio José Mantuan. Revista de Geologia USP, Publicação Especial, São Paulo, v. 6, p. 55-62, 2013.

CERVO, A. L.; BERVIAN, P. A.; SILVA, R. Metodologia Científica. 6. ed. São Paulo: Pearson Pretince Hall, 2007.

CHAIS, C.; MACHADO, C. P.; SCOPEL, A. M., TONI, D. Consumo Consciente: Uma alternativa para o Desenvolvimento Sustentável. Revista Global Manager, Passo Fundo - RS, v. 13, n. 2, p. 59-75, 2013.

CHAN, R. Y. K.; LAU, L. B. Y. Antecedents of green purchases: a survey in China. JournalofConsumer Marketing, v.17, n. 4, p. 338-357, 2000 .

COPETTI, C.; FRIZZO, C., M. Sustentabilidade, Matriz Energética e Biodiversidade: Atualizações Sociais, Políticas e Tecnologias para um Novo Direito Ambiental e Agrário. In: I SEMINÁRIO NACIONAL DE DIREITO AMBIENTAL E AGRÁRIO DA UFSM e II CONGRESSO NACIONAL DE DIREITO DAS FAMES, 2009, Santa Maria - RS. Anais...Santa Maria: Revista Eletrônica do Curso de Direito da UFSM, 2009. v. 1, p. 16-32.

CURY, C. R. J. Direito à educação: direito à igualdade, direito à diferença. Revista Cadernos de Pesquisa, São Paulo, n. 116, p. 245 262, 2002.
ESTER, P.; SIMÕES, S.; VINKEN, H. Cultural changeandenvironmentalism: a cross-national approach ofmasspublicsanddecisionmakers. Revista Ambiente e Sociedade, São Paulo, v.7, n. 2, p. 45-66, 2004.

FONSECA, M. A. S. O consumo de bens de luxo e a concentração de renda no Brasil. 2008. 43 f. TCC (Graduação) - Curso de Ciências Econômicas, Universidade Estadual de Campinas - UNICAMP, Instituto de Economia - IE, Campinas, 2008.

FURRIELA, R. B. Educação para o consumo sustentável. Ciclo de Palestras sobre Meio Ambiente - Programa Conheça a Educação do Cibec/Inep-MEC/SEF/COEA, p. 47-55, 2001.

GODECKE, M. V.; NAIME, R. H.; FIGUEIREDO, J. A. S. O consumismo e a geração de resíduos sólidos urbanos no Brasil. Revista Eletrônica em Gestão, Educação e Tecnologia Ambiental, v. 8, n. 8, p. 1700-1712, 2013.

KALAFATIS, S. P.; POLLARD, M.; EAST, R.; TSOGAS, M. H. Green marketing and Ajzen $\square \mathrm{s}$ theory of planned behavior: a cross-market examination. JournalofConsumer Marketing, v. 16, n.5, p. 441-460, 1999.

KREMER, J. Caminhando rumo ao consumo sustentável: uma investigação sobre a teoria declarada e as práticas das empresas no Brasil e no Reino Unido. PPG em Ciências Sociais. PUCSP, São Paulo, 2007. 323 p.

MARCONI, M. A.; LAKATOS, E. M. Técnicas de Pesquisa: planejamento e execução de pesquisa, amostragens e técnicas de pesquisa, elaboração, análise e interpretação de dados. 6 . ed. São Paulo: Atlas, 2006.

MATOS, R. Migração e urbanização no Brasil. Revista Geografias, Belo Horizonte, v. 8, n. 1, p. 07-23, 2012. 
MOISANDER, J.; PESONEN, S. Narratives of sustainable ways of living: constructing the self and the other as a green consumer. Management Decision, v.40, n. 4, p. 329-342, 2002.

MORAES, A. B. C.; SARTORI, E. C.; LIMA, M. B. Projeto básico para aterro sanitário no município de Itaperuna - RJ. 2017. 395 f. TCC (Graduação) - Curso de Engenharia Civil, Centro Universitário Redentor, Itaperuna, 2017.

MUCELIN, C. A.; BELLINI, M. Lixo e impactos ambientais perceptíveis no ecossistema urbano. Revista Sociedade \& Natureza, Uberlândia, v.20, n.1, p. 111-124, 2008.

PASTORE, S. et al. Consumo Consciente: Uma Análise entre os Alunos de uma Instituição de Ensino Superior da Serra Gaúcha. In: XV MOSTRA DE INICIAÇÃO CIENTÍFICA, PÓS-GRADUAÇÃO, PESQUISA E EXTENSÃO, 2015, Caxias do Sul. Anais... Caxias do Sul: Universidade de Caxias do Sul, p. 1-7, 2015.

PEREIRA, A. O. K. (Org.); HORN, L. F. D. R. Relações de consumo: Meio Ambiente. Caxias do Sul: Educs, 2009.

PORTILHO, F. Consumo sustentável: limites e possibilidades de ambientalização e politização das práticas de consumo. Cadernos EBAPE. BR, Rio de Janeiro, v. 3, n. 3, p. 01-12, 2005.

PUJADAS, C. H.; FIGUEROA, M. F.; GARCÍA, M. L.; HERNÁNDEZ, J. J.Consumo Sostenible ante laCrisis Global. Revista de Ciencia Política, Buenos Aires, n. 8, 2009.

SIMOES, R.; GIRALDI, J.; OLIVEIRA, S. Influência dos valores pessoais no comportamento «verde» do consumidor. Revista Portuguesa e Brasileira de Gestão dos Países de Língua Portuguesa, Lisboa, v.11, n. 4, p. 26-37, 2012.

SMO - Secretaria Municipal de Obras de Itaperuna. Coleta de dados e informações perti- nentes a caracterização do município quanto a gestão e manejo de resíduos sólidos, Itaperuna, 2017.

STERN, P.C.; DIETZ, T.; KALOF, L.; GUAGNANO, G. A. Values, beliefs, and proenvironmental action: attitude formation toward emergent attitude objects. Journal of Applied Social Psychology, v. 25, n.18, p. 1611-1636, 1995.

STRAUGHAN, R. D.; ROBERTS, J. A. Environmental segmentation alternatives: a look at green consumer behavior in the new millennium. Journal of Consumer Marketing, vol. 16, n.6, p. 558-575, 1999.

TOALDO, A. M. A educação ambiental como instrumento para a concretização do desenvolvimento sustentável. Revista Âmbito Jurídico, Rio Grande, XIV, n. 87, 2011.

VIEIRA, G. C.; COSTA, B. S. A prática do consumo consciente para a efetivação do direito ao meio ambiente ecologicamente equilibrado. Revista Direito Ambiental e sociedade, Caxias do Sul - RS, v. 5, n. 2, p. 261-282, 2015.

ZANIRATO, S. H.; ROTONDARO, T. Consumo, um dos dilemas da sustentabilidade. Revista Estudos Avançados, São Paulo, v. 30, n. 88 , p. 77-92, 2016.

ZYGMUNT, B. Vida para consumo: a transformação das pessoas em mercadorias. Rio de Janeiro: Zahar, 2008. 